\title{
IBN SINA (AVICENA): O INTELECTO E A CURA DA ALMA
}

Miguel Attie Filho*

SÍNTESE - Este artigo apresenta uma tradução do prólogo da obra "Al-Šifā",", escrita por Ibn Sina (980-1037 d.C.) além de discutir elementos sobre a questão da alma e do intelecto.

PALAVRAS-CHAVE - Ibn Sina. Avicena. Filosofia árabe. Alma. Intelecto.
ABSTRACT - This article presents a translation of the prologue of the work "Al-Šifā"," written by Ibn Sina (980-1037.C.) and argues elements on the question of the soul and the intellect.

KEY WORDS - Ibn Sina. Avicenna. Arabic Philosophy. Soul. Intellect.

Escrever uma obra enciclopédica na qual se ousa reunir os conhecimentos mais significativos da ciência da época não foi, de modo algum, uma prática comum no séc. XI d.C. No entanto, esse foi parte do legado deixado por Ibn Sīnā: Al-Šifä' - na qual se encontra o Kitāb al-Nafs/ Livro da alma, incluído na parte da Física. ${ }^{1}$ Sem paralelo na história da filosofia, nela reuniram-se sob sua pena, da lógica à metafísica, ${ }^{2}$ em língua árabe, tais saberes. O provocativo título

* Professor da Área de Árabe do Depto. de Letras da FFLCH da USP.

1 O presente artigo foi composto e adaptado a partir do livro ATTIE F., M. O intelecto em Ibn Sina (Avicena). São Paulo: Ed. Ateliê, no prelo. Para mais detalhes a respeito da vida e da obra de Ibn Sīnā, características da $A l$-Šifä' e do Livro da alma, sua importância histórica a partir das traduções ao latim em meados do séc. XII d.C. remetemos o leitor à introdução que oferecemos em ATTIE F., M. Os sentidos internos em Ibn Sinnā (Avicena). Porto Alegre: 2000, p. 9 a 39. Vale anotar que as fontes de nosso autor não se restringem a Aristóteles, mas incluem Al-Fārābī, Plotino e Galeno dentre outros, somada sua própria experiência como médico. Na verdade, o Livro da alma não é um comentário ao texto de Aristóteles - e surpreende o leitor acostumado à tradição de comentários à obra do mestre grego tais como alguns escritos de Ibn Rušd (Averróis). Não se encontra nesta obra de Ibn Sīnā qualquer semelhança nesse sentido, tratando-se de abordagem diversa, na qual o filósofo não se encerra nos princípios aristotélicos, acrescentando a estes uma série de novos elementos.

2 A Al-Šifā' comporta quatro tomos: Lógica, Física, Matemática e Metafísica. A Lógica compreende 9 livros: Isagoge, Categorias, Perihermeneas, Primeiros analíticos, Segundos analíticos, Dialética, Sofística, Retórica e Poética. A Física compreende 8 livros: a Física propriamente dita, O céu e o mundo, A geração e a corrupção, As ações e as paixões, Os meteoros, A alma, Os vegetais e Os animais. A Matemática é disposta em quatro livros: Geometria, Aritmética, Música e Astronomia. E finalmente a Metafísica, em 10 livros. Cf. ANAWATI, G. C. "Essai de bibliographie avicennienne". Revue Thomiste. Paris: vol. 51, p. 417, 1951. Para as respectivas partes da Al-Šifä' que foram editadas em árabe ou então traduzidas para outros idiomas, ver a relação fornecida por

\begin{tabular}{|l|l|l|l|l|l|}
\hline VERITAS & Porto Alegre & V. 52 & n. 3 & Setembro 2007 & p. 47-54 \\
\hline
\end{tabular}


geral da obra - A Cura - conferiu à sua letra prescrição, alçou o saber à condição terapêutica e estatuiu Ibn Sīnā médico da alma. O inequívoco caráter desse desejo transpira de sua autobiografia ${ }^{3}$ - repetida ao fastio - na qual o filósofo atesta a facilidade de aprendizado e a oportunidade de ter lido na biblioteca de Nuh Ibn Manșūr autores consagrados nas ciências de seu tempo. Ter ultrapassado seu primeiro mestre Al-Natīlī, ter continuado sozinho a aprender o Almagesto de Ptolomeu, os Elementos de Euclides, a Metafísica de Aristóteles, além da arte médica, não pareceu ter se constituído em árdua tarefa (!). Peculiaridades insignes que forjaram em Ibn Sīnā um caráter próprio de saber universal. Há um milênio, ser mestre em todas as ciências ainda era possível. Entretanto, a garantia do estatuto de mestria não se atingia pela mera atualização de ciências estanques: formar-se era também possuir o atilho para ligar os conhecimentos em uníssono. O paradigma do homem universal, versado em todas as ciências foi, assim, atingido em larga escala por Ibn Sīnā. Não se trata, porém, de mero recolhimento de temas consagrados, o que por si já seria valioso, mas estes amparam-se de reflexões, críticas e experiências próprias como se vê na $A l$-Šifä'. E isso fê-lo original.

A pedido de Al-Jūzjānī, discípulo, organizador e continuador da autobiografia do mestre, nasceu a obra. Ibn Sīnā, já em idade madura, iniciou-a em Hamadan e levou aproximadamente dez anos para completá-la em Isfahan, quando tinha por volta de cinquenta anos. Morreu poucos anos depois de sua composição. O discípulo lhe pedira que escrevesse comentários às obras de Aristóteles. A recusa de Ibn Sīnā e a idéia da reunião dos saberes constitui-se em fato notável. Herdeiro da tradição peripatética e neoplatônica em língua árabe, sob seu projeto estende-se uma concepção própria da classificação das ciências e da possibilidade de realizá-las. ${ }^{4}$ Não obstante seguir de perto a estrutura de classificação da escola peripatética - declarando no prólogo que fará o discurso sob tal estilo - a recusa do comentário estabelece novo horizonte na história do autor: equiparar-se e mesmo ultrapassar Aristóteles e Al-Fārābī? Revigorar as ciências em nova chave de leitura? Legar à humanidade uma síntese das ciências de sua época? Pensamentos pertinentes que ombreiam a Al-Šifā' e fazem-na, no curso da história da filosofia, simultaneamente, convergência e dispersão, e marco nessa história. Seu prólogo fala por si:

JANSSENS, J. L. An Annotated Bibliography on Ibn Sīnā (1970-1989). Leuven: University Press, 1991, p. 3-13.

3 A autobiografia completa encontra-se em edição bilíngüe em GOHLMAN, W. E. The life of Ibn Sina. New York: State University of New York Press, 1974, pp. 17-89. Cf. também AFNAN, S. Avicenna: His Life and Works. London: Unwin Brothers Limited, 1958, p. 57-82.

4 Para uma recuperação das ligações de Ibn Sīnā com a tradição aristotélica, sua concepção da história da filosofia e questões pertinentes à classificação das ciências, Cf. GUTAS, Avicenna and the aristotelian tradition, New York, 1971. 


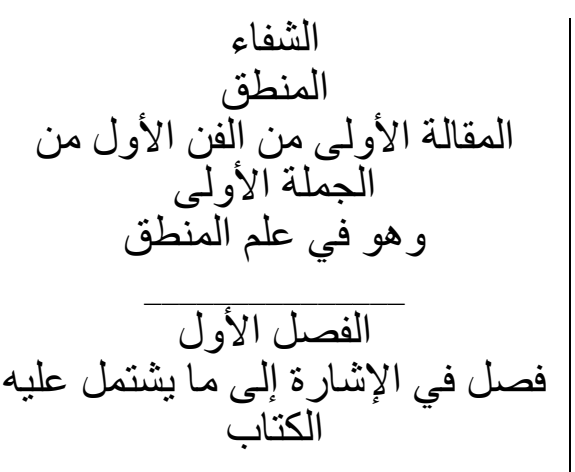

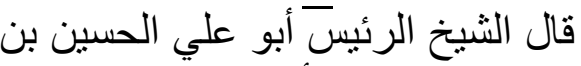

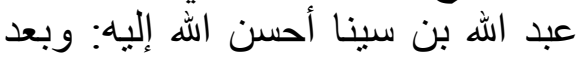
أهمد الله والثناء عليه كما هو أهله

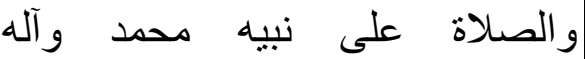
الطاهرين فإنّ غرضنا في هذا الكتاب

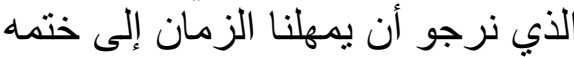

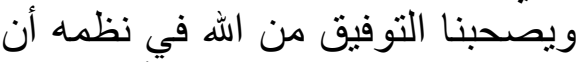

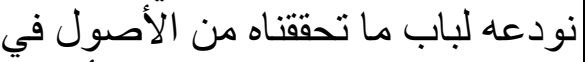
العلوم الفلسفية المنسوبة إلى الأقدمين العين

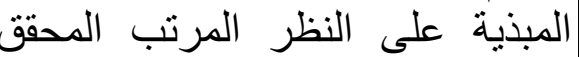

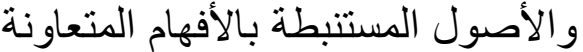

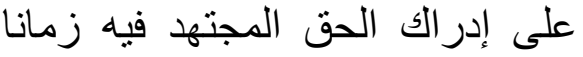

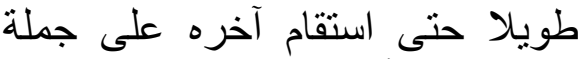
اتفقت عليها أكثر الآراء وهجرت آخره معها

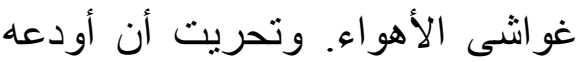

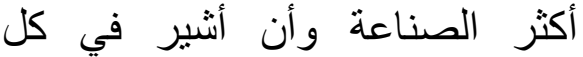

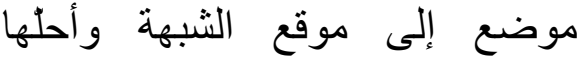
بايضاح الحقيقة بقدر الطاقة وأورد الأل

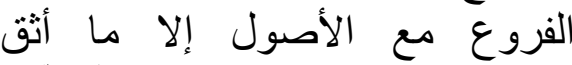

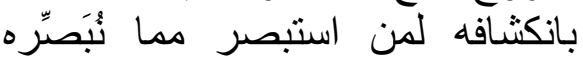

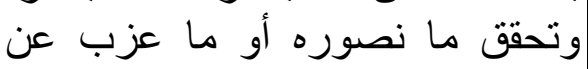

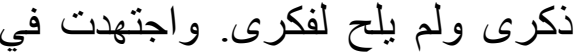
|ختصار الألفاظ جدا ومجانبة التكرار

\section{A CURA}

Lógica

Tratado I - Parte I - Tomo I.

\section{Sobre a ciência da Lógica}

\author{
Primeira seção
}

Seção a respeito da indicação do conteúdo do Livro

Disse al-šaīh al-ra'īs 'Abū 'Alī al-Ḥussain bin 'Abd Allāh bin Sīnā - que Deus o beneficie; louvado seja Deus - e que sejam as loas para Ele - pois é digno disso; que a bênção esteja sobre seu profeta Muhammad e seus familiares, os puros:

"Nosso objetivo neste livro - e esperamos que nos seja dado tempo para concluí-lo e que nos acompanhe o êxito de Deus em sua feitura - é consignar o cerne do que verificamos dos fundamentos das Ciências filosóficas atribuídas aos antigos, com base na análise metódica verificada e nos fundamentos deduzidos pelas compreensões que se auxiliam para perceber o que é verdadeiro e que mereceu um esforço constante desde longo tempo, até se estabelecer num conjunto a respeito do qual a maioria das opiniões converge abandonando-se, assim, as opiniões quiméricas.

Procurei consignar nele grande parte da arte; apontar em cada lugar a ocorrência da ambigüidade, solucionando-a pela elucidação da verdade, na medida do possível; indicar os desdobramentos com os fundamentos, exceto o que acredito estar claro para quem entendeu o que estamos informando e verifica o que descrevemos, ou aquilo que esqueci e não me ocorreu. Esforcei-me em abreviar consideravelmente os temas e evitei to- 
أصلا إلا ما يقع خطا أوسهوا وتتكبت

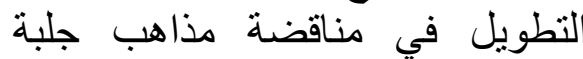

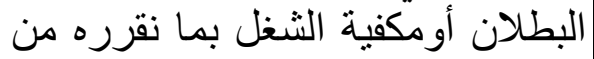
الأصول ونعرفه من القو انين. و لايوجد التداء في كتب القدماء شيء بعتد به إلاوفن الإند

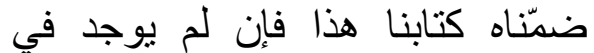

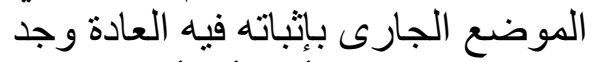

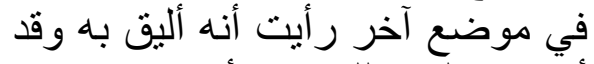
أضفت إلى ذلى ذلك مما أدركته بفكرى أنه

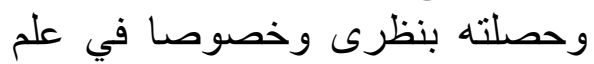
الطبيعة و ما بعدها وفي علم المنطق.

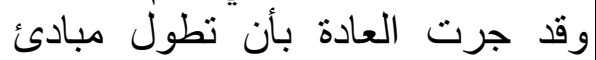

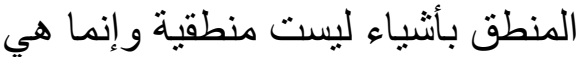

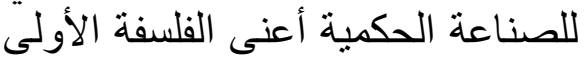

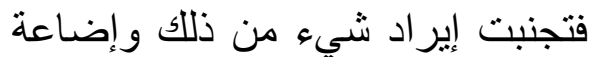

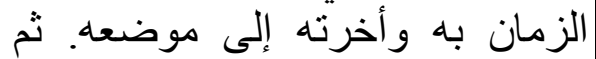

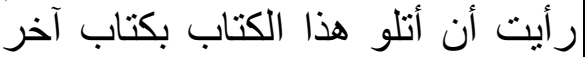

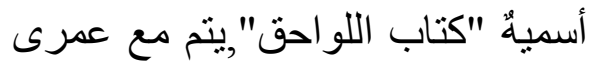
ويؤرخ بما يفرغ منه في كل سن سنة

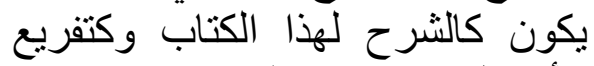
الأصول فيه وبسط الموجز من معانيه

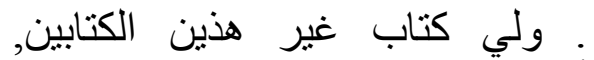

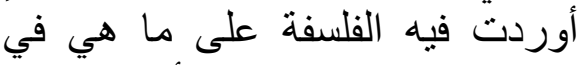
الطبع و على ما يوجبه الرأى الصريح

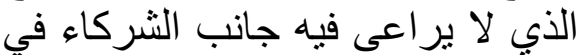

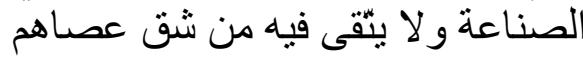
ما يتقى في غيره وهو كتابي في

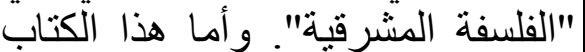

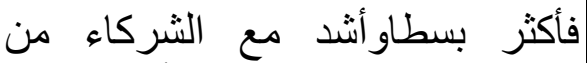

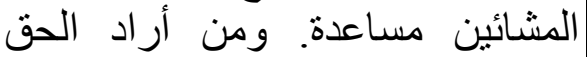

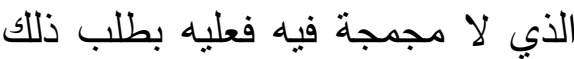
الكتاب ومن أر اد الحق على طريق فيه فيه فيه لريه

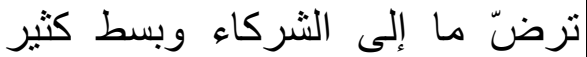

talmente as repetições, exceto o que tenha se dado por engano ou distração. Evitei estender-me na contestação de doutrinas claramente falsas ou suficientemente trabalhadas pelo que constatamos nos fundamentos e do que conhecemos dos cânones.

Nada existe nos livros dos antigos que não incluímos neste nosso livro. Caso não esteja fixado no lugar de costume, estará em outro que achei mais conveniente, tendo sido complementado com aquilo que foi fruto de minhas reflexões e concluído por meio de minha análise, especialmente na Ciência da Natureza, na Metafísica e na Ciência da Lógica. Era costumeiro prolongar os princípios da Lógica com coisas que não cabem à Lógica por pertencerem à arte da sabedoria, isto é, a Filosofia Primeira e, por isso, evitei abordar algo a esse respeito e, para não perder tempo com isso, posterguei-o ao seu lugar próprio.

Depois, pensei em dar seguimento a esse livro com um outro que chamo Livro dos apêndices, que será terminado até o final de minha vida, e será datado a cada ano que se completar. Ele será como um comentário a esse livro ou um desenvolvimento dos fundamentos que aqui estão, numa exposição concisa de suas noções.

Tenho outro livro além desses dois em que expus a filosofia como ela naturalmente é e conforme o que se exige de uma opinião franca, isto é, não seguindo o ponto de vista dos colegas da arte, e nem me precavendo de ruptura ou oposição a eles como fiz alhures. E é meu livro A Filosofia oriental. Quanto a este livro, ele é mais simplificado e mais condizente com os colegas peripatéticos. Quem quiser a verdade sem circunlocução, deve dirigir-se àquele livro, e quem quiser a verdade de forma tal a se conciliar com os colegas e 


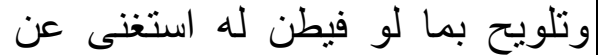

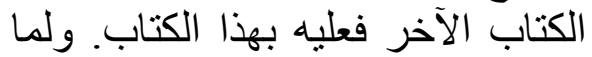

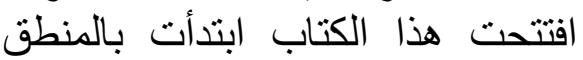

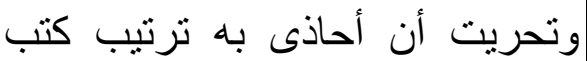
صاحب المنطق وأوردت في ذللك من تن

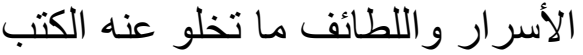

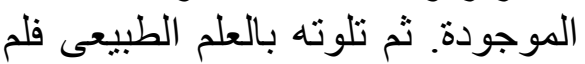
يتفق لي في أكثر الأثياء محاذ الهاذاة تصنيف المؤتث به في هذه الهن الصناعة

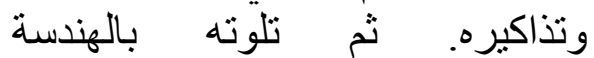
فاختصرت لأوقليدس اختصار ا لطيفا وحللت فيه البه التهنيه الثبه واقتصرت عليه.ثم أردفته باختصار كذلك لكتاب المجسطى في

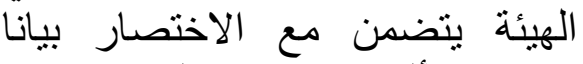
وتفهيما و ألحقت بـه من الزيادات بعد الأهد

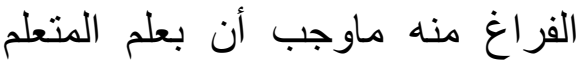

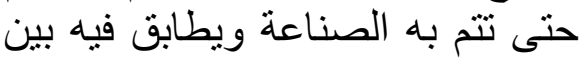
الأحكام الرصدية والقو انين الطبيعية.

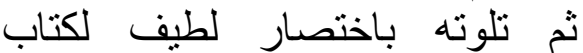
المدخل في الحساب. ثم ختمت صناعة لـارة الرياضيين بعلم الموسيقى على الوجه

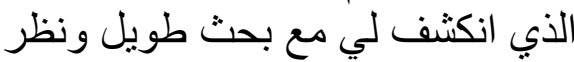

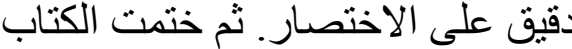
بالعلم المنسوب إلى الإخى ما بعد الطبيعة

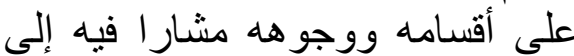

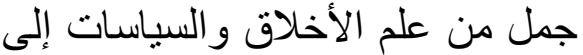
أن أصنف فيها كتابا جامعا مفردا.

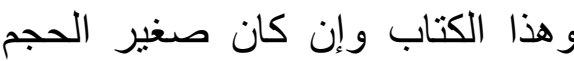

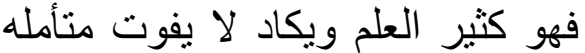

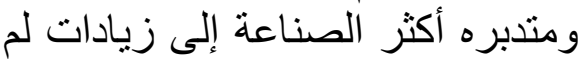

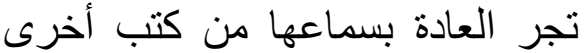
|وأول الجمل التي فيه هو علم المنطق. ter mais simplificação e glosas do que já foi mencionado, pode dispensar aquele livro e seguir por este.

Iniciei este livro começando pela Lógica e nele procurei seguir a ordenação dos livros do autor da Lógica, indicando nele alguns segredos e coisas apuradas inexistentes em outros livros. Dei prosseguimento a esta parte com a Física mas nessa disciplina não acompanhei de perto, na maioria das coisas, sua classificação e seu memorial. Segui, então, pela Geometria, resumindo o livro Elementos de Euclides, com um bom resumo, trazendo soluções para ambigüidades, mas sem me prolongar muito. Depois, prossegui com um resumo do mesmo tipo, do livro sobre astronomia, o Almagesto, incluindo, além do resumo, um índice e algumas explicações. Anexei nele, ainda, alguns adendos, terminando-o com o que é necessário para o conhecimento dos aprendizes para dominar a disciplina e fazer correlações entre os princípios da astronomia e as leis naturais. Em seguida, apresentei um bom resumo do livro Introdução à aritmética e concluí a disciplina dos matemáticos com a Música como foi revelada para mim, além de uma pesquisa longa e uma análise minuciosa do resumo. Finalizei o livro com a Ciência que diz respeito à Metafísica segundo suas divisões e seus aspectos, fazendo nele menções à Ciência da Ética e da Política para, a partir do que componho uma coletânea separada.

Este livro, embora pequeno no volume traz muito conhecimento da Ciência. E quem o examina e o utiliza com afinco consegue quase dominar a maioria das disciplinas pois ele contém adendos que nunca foram vistos em outros livros. O primeiro conjunto que ele traz versa sobre a Lógica. Mas antes de adentrar à Ciência da Lógica, indicamos resu- 


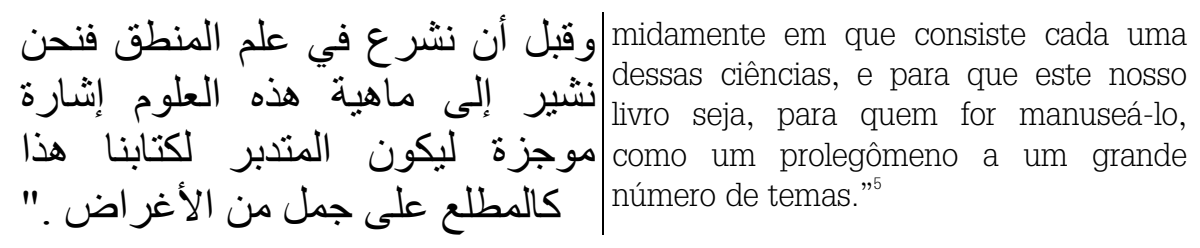

$\mathrm{Sob}^{5}$ tais fundamentos alinha-se, pois, o referido legado. No conjunto da harmonia das ciências, Ibn Sīnā orquestra sua composição iniciando pela Lógica, seguida da Física, da Matemática e, por fim, da Metafísica, consumada com um estudo sobre a moral, último livro da obra. A ordem nada tem de aleatório e indica, dentre outras coisas, circularidade e interpenetração das disciplinas. Assim, desenha-se pela mão do mestre uma estrutura e um projeto de ciência próprios. Apesar disso, algumas respostas só são possíveis na trilha da tradição da qual é herdeiro.

O Kitāb al-Nafs - Livro VI da Física ${ }^{6}$ - insere-se nesse conjunto, respondendo remotamente à questão colocada por Aristóteles em seu De Anima a respeito das condições de possibilidade de uma ciência da alma e a respectiva adequação do método mais indicado.? A pergunta a respeito da alma humana é a pergunta a respeito de sua natureza. Questões da filosofia, questões ancestrais. Basta, pois, recuperá-la e ver emergir uma miríade de teorias. Tarefa insólita de convencimento sempre duvidoso a inundar de respostas hipotéticas inúmeras outras questões daí procedentes. Pergunta intermitente cujas soluções ainda não

5 Na classificação proposta por Anawati, a Al-Šifā' encontra-se catalogada entre as obras de filosofia geral sob o n. 14, mencionada a existência de 105 manuscritos. Cf. ANAWATI, G. C., "Essai de bibliographie avicennienne". Revue Thomiste. Paris: vol, 51, p. 417. Para verificar as interpretações diversas das passagens mais importantes, Cf. GUTAS, Avicenna and the aristotelian tradition. Leiden: Brill, 1998, pp. 49-54 em que se apresenta uma tradução - não do mesmo manuscrito com algumas notas indicativas a respeito de algumas das dificuldades que aí se encontram. Cf. também uma tradução parcial em GUERRERO, Avicena, Madrid: Ed. Del Orto, 1994, p. 53-55.

${ }_{6}^{6} \quad$ Em sua introdução, Ibn Sīnā fornece um quadro geral dos livros que já foram escritos na parte da Física assim como indica os que virão em seguida. A hierarquia dos seres físicos pode ser verificada por meio da forma ascencional com que são divididos e apresentados os livros e seus respectivos temas. Assim como Aristóteles, Ibn Sīnā classifica a psicologia entre as ciências naturais, sendo ela um ramo da Física, tendo por objeto a alma do ser animado, do $\zeta \omega o v \varepsilon \mu \psi v \chi 0 v$. O estudo da vida, começando no sexto livro, inicia-se pela análise da alma naquilo em que há de comum entre o homem, os animais e as plantas. Por isso os tratados sobre os vegetais e os animais vêm depois do Livro VI. Assim como o estudo da Física introduz o estudo do mundo material, o Kitāb al-Nafs introduz o estudo do mundo biológico. Cf. ATTIE, Os sentidos internos, op. cit., p. 36-44. A seqüência, contida no prefácio do Livro da alma, lembra a ordem contida nos Metereológicos de Aristóteles. "Tratamos precedentemente das causas primeiras da natureza, de tudo o que concerne ao movimento natural, da translação ordenada dos astros na região superior, dos elementos corporais, de seu número, suas qualidades, suas transformações recíprocas e, enfim, da geração e da corrupção consideradas sob seu aspecto geral. Nesse programa de pesquisas resta examinar a parte que, em todos nossos predecessores, traz o nome de meteorologia. (...) Uma vez estudados esses sujeitos, veremos se podemos utilizar o mesmo método para o caso dos animais e das plantas consideradas em geral e em particular. Quando terminarmos essa exposição poderemos, sem dúvida, colocar um ponto final em todo o programa de pesquisa que fixamos no início." Cf. ARISTOTE, Météorológiques, Paris: Les Belles Lettres, 1982, Livro I, p. 2s.

Cf. ARISTOTE, De l'âme, Trad. Tricot. Paris: J. Vrin, 1965, I, 1 402a - 403b15. 
foram suficientes. Seguidamente revestida de outras formas, de outras vozes, de outras línguas e de outros tempos dividiu-se por novas disciplinas, multiplicou-se por outras, foi rechaçada por algumas, voltando a seguir por novos caminhos, morrendo e renascendo como a escapar de respostas definitivas. Nessa medida, pois, a ciência da alma de Ibn Sīnā tem tempo e lugar para ser contemplada. As respostas, sendo históricas assim como os conceitos, obriga que, nesse caso, sua correta compreensão se efetue no âmbito da universalidade e da harmonia buscada pelo paradigma condutor do espírito da época. Lá, os saberes se entrelaçam. De qualquer disciplina que se retire uma afirmação ouvem-se ecos nas demais, respondendo em uníssono. Por isso, a ciência da alma liga-se e implica ética, política, metafísica, cosmologia e lógica dentre outras. Recuperar a narrativa de Ibn Sīnā sobre a alma é, no horizonte mais amplo, recuperar o próprio tecido da história da filosofia, sulcado nesse período e nesse idioma.

Por sua vez, o tema do intelecto se reveste, no Livro da alma e na Metafísica como o ápice da narração, cume teórico e laço das ciências. A questão não surge, porém, do acaso e destituída de história mas, antes, insere-se numa sólida tradição de pensadores dentre os quais podem ser lembrados Teofrasto, Alexandre de Afrodísias, Temístio, Tomás de Aquino e Ibn Rušd (Averróis), ${ }^{8}$ para ficar nos mais conhecidos. No recuo histórico a fonte peripatética mais diretamente ligadas a isso foi o próprio De Anima de Aristóteles. ${ }^{9}$ Os problemas levantados - e muitas vezes não respondidos - pelo filósofo grego a respeito da alma humana foram inspiração fecunda que gerou, por sua vez, as mais díspares interpretações ao longo da história da filosofia, cujos autores citados acima tão bem ilustram. Contudo, se por um lado as questões colocadas por Aristóteles a respeito da natureza da alma e suas relações com o corpo já eram tema presente na filosofia pré-aristotélica - e mesmo antes que a filosofia ocupasse o cenário da antiga Grécia - por outro lado, as relações entre "alma" e "intelecto" não adquiriram maior luminosidade a não ser a partir dos escritos de Platão, de quem Aristóteles também foi tributário. Nessa medida, se o $D e$ Anima de Aristóteles contemplou um fértil passado dos caminhos que a tradição filosófica percorrera antes dele, também apontou direções de um fértil futuro por caminhos que levaram a filosofia a fazer sua história em outras línguas, em outras terras, por outros povos e em outros tempos.

Assim, pela linha de quase dois mil anos, dos escritos de Aristóteles ao final da Idade Média, a cognata contiguidade dos termos vovs, عقل e intelligentia reflete uma parte do caminho da história da filosofia através dos séculos, das terras e das três diferentes culturas sob as quais se vincularam tais termos. Gregos, árabes e latinos, ao adotarem os princípios da filosofia viram-se, ao longo da história, rendidos a criar em suas respectivas línguas, nomes que melhor pudessem reproduzir as inovações do pensar filosófico. O caminho percorrido na

\footnotetext{
8 Cf. AVICENNA, Liber de Anima seu Sextus Naturalibus. Leuven: Brill, 1968 - Verbeke, Introd. IV-V, p. 13-46 e p. 59-72.

9 Cf. o papel do De anima de Aristóteles na formação da falsafa em GUERRERO, R. R. "La recepcion arabe del De anima de Aristóteles: Al-Kindi e Al-Farabi. Madrid: Consejo Superior de Investigaciones Científicas, 1992.
} 
cunhagem de novos termos seguiu a máxima dos neologismos: procurar no uso corrente da linguagem algum termo capaz de ser adaptado, por aproximação e associação, para reproduzir com certa fidelidade o sentido ora buscado. Assim, uma raiz mais remota do termo vous / nous ${ }^{10}$ poderia fazê-lo derivar de "faro" no sentido do discernimento, de um certo tipo de percepção do espírito capaz de apreender determinada coisa ou situação. Por sua vez, o termo عقل /aql 'al remeteria a uma raiz que significa "atar", "ligar" e, mais precisamente, "prender", termos oriundos supostamente do substantivo عقال / iqal - uma espécie de corda com a qual se prendiam as patas dos camelos (!) - e, por extensão, ter-se-ia derivado e sido aplicado ao pensamento em seu ato de apreender as coisas que lhe são próprias. Quanto ao termo intelligentia, ${ }^{12}$ a etimologia tradicional ensinou que o ato de inteligir seria algo como "ler no íntimo, ler dentro", no sentido do entendimento humano que apreende o íntimo das coisas, suas essências, em contraste ao conhecimento sensível e imaginativo que permaneceria na exterioridade do que é conhecido. Em largo espectro, portanto, vovs, عقل e intelligentia guardam um núcleo comum de significado mas que, por sua vez, é difícil de ser contemplado por uma única tradução. Afinal, entre o uso do termo pelos primeiros pensadores gregos e o uso dos últimos latinos ao final da Idade Média perto de dois mil anos foram passados e, nesse fio de tempo, cada uma das três culturas - grega, árabe e latina - viveu um cenário singular e irrepetível, no qual as nuances de cada um dos três termos se apresentam por certas particularidades que não se esgotariam em poucas linhas. Contudo, de nossa parte, desejamos que estas poucas sejam portadoras e condutoras de incentivo a outros estudos, espelhando de modo mais detido tal tríade lingüística, e justificando o grau crescente no qual se encontram as pesquisas da falsafa no Brasil.

10 Cf. ocorrência e evolução do termo em WEBER, E. Encyclopédie Philosophique Universelle. Paris: PUF, 1990, p.1773. Cf. PLATÃO, Crátilo, para origem de termos gregos, particularmente 411a 416a e 407a - 407 c. sobre o vocabulário em questão.

11 Para maior aprofundamento do termo 'aql e de suas relações com termos próximos tais como "razão, sabedoria e conhecimento" cf. a introdução de Guerrero em AVERROES, Sobre Filosofia y Religión. Navarra: Servicio de Publicaciones de la Universidad de Navarra, 1998, p. 9-18. Cf. também ARKOUN, M. La pensée arabe. Paris: PUF, p. 63-65. O termo em questão não é nomeado no Alcorão como sendo uma faculdade da alma mas os 49 empregos do verbo 'aqala visam a atividade de uma faculdade definida, tal como encontra-se na Surata 2/44: أفلا تعقلون / Não compreendeis?

12 Para a evolução e os diferentes sentidos do termo Cf. WEBER, E. Encyclopédie Philosophique Universelle. Paris: PUF, 1990, p. 1330. Na Idade Média, intellectus e intelligentia designam, geralmente, a parte superior da alma ou do espírito e seu respectivo ato de conhecimento. O termo "inteligível" geralmente designa o objeto da apreensão pelo intelecto em oposição ao que é apreendido pelos sentidos. Uma notável distinção é feita por Boécio: "A razão transcende o conhecimento sensível mas ela é, por sua vez, transcendida pela intelligentia, pela intuição intelectiva que conhece e julga do ponto de vista supremo." Cf. BOÉCIO Consolo da Filosofia V, pr. 4, n. 30 e n. 32). "Se a razão é do homem, a intelligentia é de Deus "(ibid, pr. 5 n. 4). No Kitāb alNafs , Ibn Sīnā parece seguir em linhas gerais o sentido de que a inteligência se realiza no homem como faculdade intelectual - intelecto - manifestando-se por meio racional, discursivo. Mas também considera a possibilidade do conhecimento se dar por intuição, de modo imediato, de um só golpe, sem a intermediação do aprendizado convencional, caso intitulado "intelecto sagrado". 